\title{
Paraty a Estrada Real: A Química do Envelhecimento da Cachaça
}

\section{Paraty the Royal Road: The Chemistry of Cachaça Aging}

DOI: 10.46814/lajdv3n1-003

Recebimento dos originais: 30/10/2020

Aceitação para publicação: 23/12/2020

\section{Elias de Souza Monteriro Filho}

UNESP - Instituto de Química

Rua prof. Francisco Degni, 55 - Araraquara, SP, CEP: 14.80-0060

Angélica Ramos da Luz

UNESP - Instituto de Química

Rua prof. Francisco Degni, 55 - Araraquara, SP, CEP: 14.80-0060

\section{Raul Natale Junior}

UNESP - Instituto de Química

Rua prof. Francisco Degni, 55 - Araraquara, SP, CEP: 14.80-0060

\section{Miguel Ruiz}

UNESP - Instituto de Química

Rua prof. Francisco Degni, 55 - Araraquara, SP, CEP: 14.80-0060

\section{João Bosco Faria}

UNESP - Faculdade de Ciências Farmacêuticas

Rod. Araraquara - Jaú Km 1, - Araraquara, SP, CEP. 14801-902

E-mail: fariajb@fcfar.unesp.br

\section{Sinara München}

UFSM - PPG Educação em Ciências: Química da Vida e Saúde Av. Roraima, 1000, Santa Maria-RS CEP 97105900

E-mail: sinaramunchen@yahoo.com.br

\section{Martha B. Adaime}

UFSM - PPG Educação em Ciências: Química da Vida e Saúde

Av. Roraima, 1000, Santa Maria-RS CEP 97105900

\section{Leinig Antonio Perazolli}

UNESP - Instituto de Química

Rua prof. Francisco Degni, 55 - Araraquara, SP, CEP: 14.80-0060

E-mail: leinig.perazolli@unesp.br 


\section{RESUMO}

Desde o desenvolvimento do Ciclo do Ouro, Paraty mostrou destaque na produção de cachaça, que era consumida tanto pelo mercado nacional quanto utilizada no escambo por escravos na África e por ouro nas minas, sendo transportada pela Estrada Real. O transporte era realizado em tonéis de carvalho para fora do país e em tonéis de madeiras nacionais para o mercado local. Com o tempo foi observado que cada tipo de madeira incorporava à cachaça odores e sabores diferenciados. Considerando que a cachaça é produzida da fermentação do caldo, diferente do Rum, que é produzido da fermentação do melaço, e que o envelhecimento em diferentes tipos de madeiras adicionavam características sensoriais e químicas específicas, permitiu estabelecer a Cachaça como um produto genuínamente Brasileiro.

Palavras-chave: Paraty, História, Química, Cachaça, Envelhecimento.

\section{ABSTRACT}

Since the development of the Gold Cycle, Paraty has shown prominence in the production of cachaça, which was consumed both by the national market and by slaves in Africa and by gold in the mines, being transported by the Estrada Real. The transport was carried out in oak barrels outside the country and in national wood barrels for the local market. Over time it was observed that each type of wood incorporated different odors and flavors to the cachaça. Considering that the cachaça is produced from the fermentation of the juice, different from the Rum, which is produced from the fermentation of molasses, and that the aging in different types of wood added specific sensory and chemical characteristics, allowed to establish the Cachaça as a genuinely Brazilian product.

Keywords: Paraty, History, Chemistry, Cachaça, Aging.

\section{INTRODUÇÃO}

A cachaça, é a segunda bebida mais consumida pelos brasileiros, com consumo estimado em 70 milhões de doses diárias (Lima et al, 2006). Esta bebida é muito apreciada por apresentar sabor e aroma característicos, provenientes dos processos fermentativos, de destilação e opcionalmente de envelhecimento.

Para ser considerada envelhecida, a composição final do produto deve se apresentar pelo menos $50 \%$ do seu volume envelhecido em tonéis de madeira, pelo período mínimo de um ano (Odello et al, 2009). As características sensoriais específicas da bebida se dão pela presença de pelo menos $1 \%$ em massa de compostos secundários como alcoóis superiores, ésteres, ácidos carboxílicos e compostos carbonílicos que são formados durante a produção e envelhecimento da aguardente (Nascimento et al, 1998).

Considerando a importância desse produto no cenário histórico, econômico e social brasileiro e a possibilidade de sua abordagem no ensino de química, foi realizado um estudo histórico e químico da cachaça para a construção de um material de referência para o estudo do tema, assim como para planejamento de atividades didáticas. 


\section{A ESTRADA REAL E O ENVELHECIMENTO DA CACHAÇA: ASPECTOS} HISTÓRICOS

Com a descoberta do ouro na região de Minas Gerais, no final do Século XVII, o foco da economia brasileira abandonou a já decadente produção de açúcar para dar inicio a extração de minérios. Para garantir que todos os devidos impostos dessa mineração seriam pagos à Coroa portuguesa, o governo construiu e obrigou que todo o fluxo de ouro e de escravos fosse feito através da Estrada Real, o que criou uma importante rota de comércio ligando a região de Paraty e as minas, até a capital, no Rio de Janeiro, ilustrada na Figura 1.

Figura 1: Mapa da antiga e nova Estrada Real

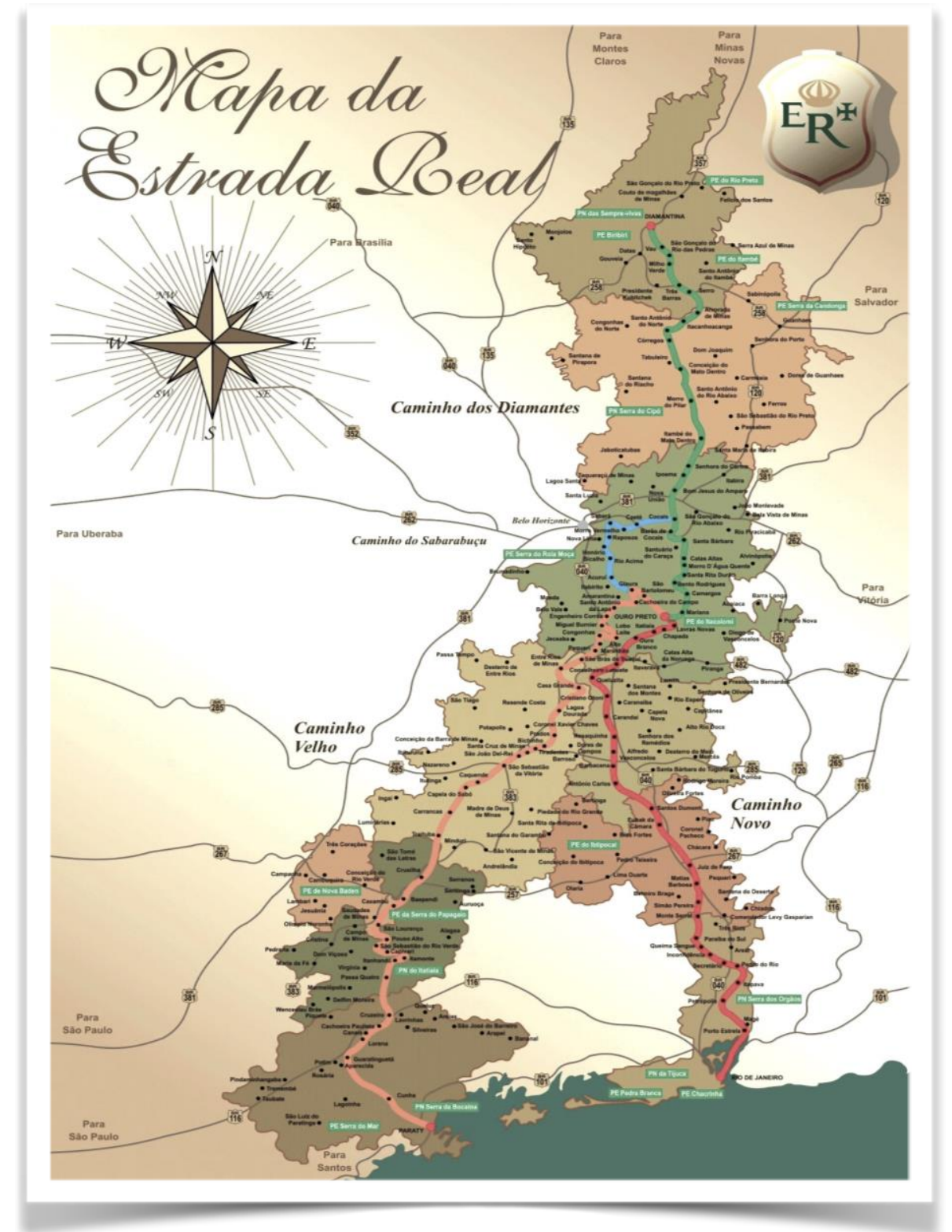


Além de abastecer o mercado nacional, a cachaça era também uma importante mercadoria na troca ao se negociar escravos com as tribos africanas. Para que a bebida pudesse ser levada até a Europa ou a África, era exigido que os barris utilizados para o armazenamento e transporte fossem confeccionados em carvalho. A razão desta exigência era devido ao contato da madeira com a bebida acabava por alterar as características sensoriais do produto. Por já ser utilizado no armazenamento de outras bebidas destiladas européias, o carvalho fornecia as características que menos destoavam das outras bebidas tradicionais européias.

A obtenção desses barris e tonéis de carvalho se tornava uma tarefa cara e complicada, uma vez que o país não possuía o carvalho necessário para a produção destes tonéis. Devido a essa questão, a cachaça destinada a exportação era armazenada e transportada em tonéis de carvalho trazidos da Europa, enquanto os tonéis destinados ao consumo local eram feitos com madeiras nacionais que mostrassem características físicas adequadas, tais como o Ipê-amarelo, Umburana, Bálsamo, Sassafras ou Amendoim.

Tanto os longos períodos de viagem quanto o armazenamento local nestes tonéis provocavam mudanças sensoriais relacionadas ao envelhecimento da bebida, o que conferia características específicas de cor, sabor e aroma da cachaça, relacionadas a cada tipo de madeira utilizada (Trindade, 2006; Miranda, 2008).

\section{ENVELHECIMENTO: ASPECTOS QUÍMICOS}

\subsection{A ESCOLHA DA MADEIRA}

O envelhecimento da cachaça é um importante parâmetro para a melhoria de sua qualidade sensorial, uma vez que esta etapa afeta desde a intensidade da cor, que adquire tons que vão de um amarelado leve à tons próximos ao marrom, até o aroma e sabor, que passa a ter características amadeiradas, doces, ou frutadas, dependendo do tempo de envelhecimento e da madeira utilizada. além disso o processo também também diminui os fatores sensoriais considerados negativos, como a acidez, o sabor alcoólico intenso (Otello et all, 2009).

Durante o processo de estocagem da cachaça, se considera como processo de envelhecimento somente a situação na qual o produto é armazenado em barril ou tonel de madeira por um período de pelo menos um ano. Os tipos de madeira mais escolhidos para a construção dos tonéis são o bálsamo, jatobá, umburana, canéla-sassafras, jequitibá, ipê amarelo ou amendoim. Nesta etapa, o contato da bebida com a madeira do tonel irá gradativamente provocar diversas reações químicas que alterarão o produto final. 
Figura 2: Os diferentes estágios de envelhecimento da cachaça

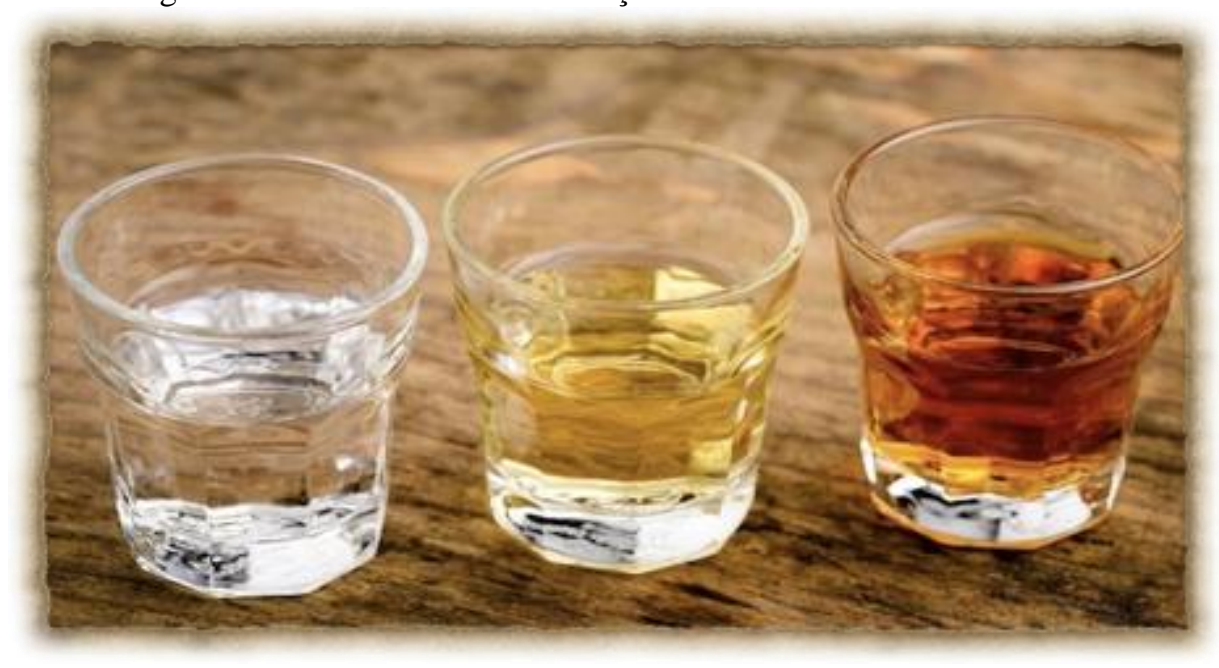

Devido a semipermeabilidade da madeira, o processo de envelhecimento permite tanto a perda de determinados componentes ao ambiente, tais como a água e o etanol, quanto a entrada do oxigênio, permitindo a ocorrência do processo de oxidação dos aldeídos e álcoois superiores gerados na fermentação do mosto.

Dentre os compostos provenientes da madeira que são incorporados a bebida, estão os compostos fenólicos, flavonóides (figura 3) e taninos (Dewik, 2002), assim como produtos da decomposição parcial de macromoléculas, como lignina (figura 5) e celulose, em monômeros solúveis, como aldeídos e ácidos fenólicos (Trindade, 2006; Ventura e Giraldez, 2006).

Figura 3: Luteonina, Quercetina e Rutina. Exemplos de flavonoides encontrados em madeiras. Observando suas estruturas, é possível notar que a estrutura principal das moléculas é muito semelhante. A adição de diferentes radicais gera produtos distintos.produtos (Dewik, 2002).<smiles>O=c1cc(-c2ccc(O)c(O)c2)oc2cc(O)cc(O)c12</smiles><smiles>O=C1c2c(O)cc(O)cc2OC(c2ccc(O)c(O)c2)C1(O)CC1CCCCCC1</smiles>

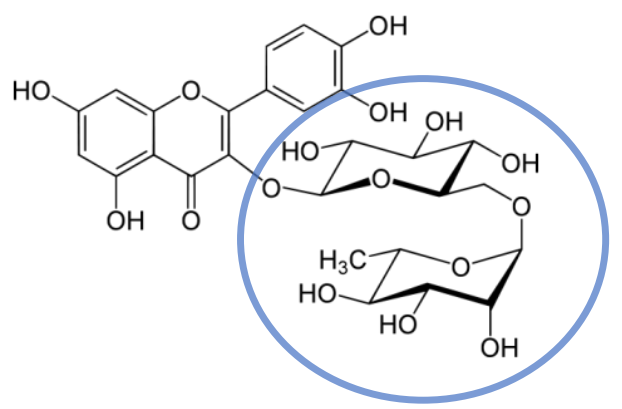


Figura 4: Exemplo da complexidade da molécula química da lignina. (Infoescola, 2012).

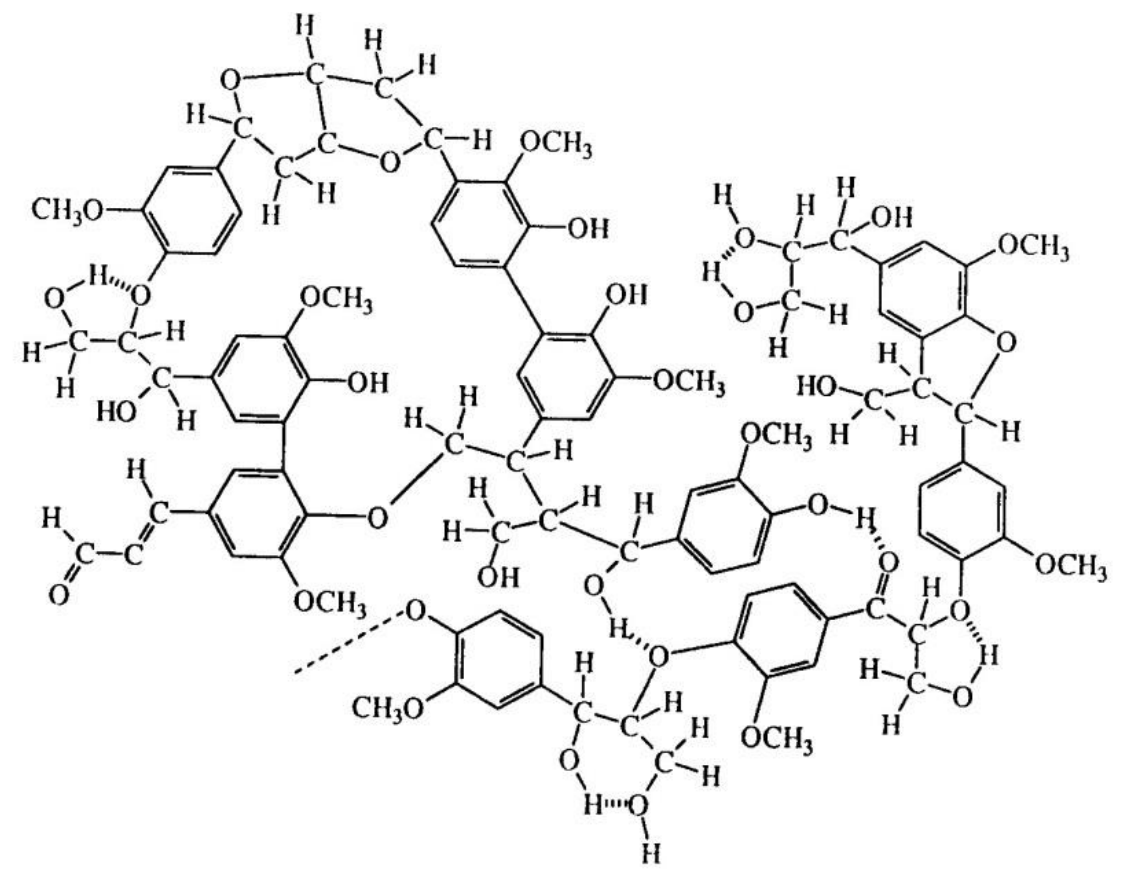

Para que a madeira possa ser considerada apropriada para a construção de tonéis, ela deve possuir algumas características. A primeira delas é uma alta densidade, para garantir uma boa impermeabilidade e evitar uma grande perda do volume da bebida para o ambiente. A madeira também deve possuir uma boa resistência mecânica e durabilidade, para diminuir o risco de rachaduras, deformações e dano causado pela ação do tempo ou de fungos e insetos (Trindade, 2006).

A escolha da madeira também irá determinar quais substâncias serão extraídas para a cachaça durante o processo de envelhecimento. Através do uso de análise cromatográfica, é possível identificar as principais moléculas extraídas que diferenciam as alterações sensoriais causadas por cada madeiras. As figuras entre 5 a 8 ilustram quais são. essas moléculas:

Figura 5: Principais moléculas que caracterizam o envelhecimento em Amburana.

\section{AMBURANA}<smiles>O=C1CC(c2ccc(O)cc2)Oc2cc(O)cc(O)c21</smiles>

1 (narigenin; $272 \mathrm{Da})$<smiles>COc1ccc(-c2coc3cc(O)c(OC)c(O)c3c2=O)cc1</smiles>

2 (pectolinarigenin; $314 \mathrm{Da}$ )<smiles>COc1ccc(C2C(=O)c3c(O)cc(O)cc3OC2c2ccc(O)cc2)cc1</smiles> 
Figura 6: Principais moléculas que caracterizam o envelhecimento em Jequitibá.

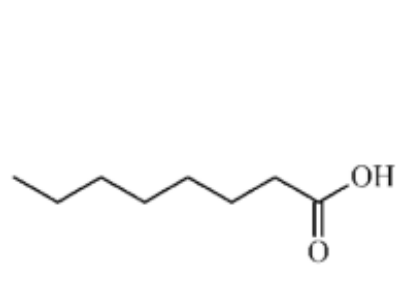

4 (caprylic acid, $144 \mathrm{Da})$

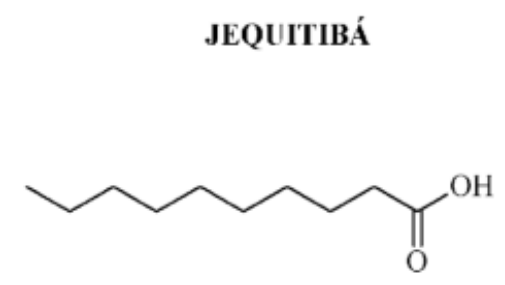

5 (capric acid, 172 Da)<smiles>O=C1CC(c2ccc(O)cc2)Oc2ccc(O)cc21</smiles>

6 (liquiritigenin; $256 \mathrm{Da}$ )

Figura 7: Principais moléculas que caracterizam o envelhecimento em Bálsamo.<smiles>COc1ccc(-c2coc3c(O)cc(O)cc3c2=O)cc1</smiles>

Figura 8: Principais moléculas que caracterizam o envelhecimento em Carvalho.

\section{OAK}<smiles>CCOC(=O)c1cc(O)c(O)c(O)c1</smiles>

11 (ethyl gallate; $198 \mathrm{Da})$<smiles></smiles>

12 (ellagic acid; 302 Da)

\subsection{AS REAÇÕES ENVOLVIDAS NO PROCESSO DE ENVELHECIMENTO}

De acordo com os estudos de Miranda (2008) durante o processo de envelhecimento ocorre a intensificação na concentração de ésteres, de álcoois como o $n$-propanol, isobutílico e isoamílico. O envelhecimento é resultado de uma série de reações entre o componentes químicos da cachaça e aqueles que são extraídos da madeira, os quais também são responsáveis pela coloração diferenciada da bebida envelhecida. 
Mesmo que o processo de envelhecimento ainda não esteja completamente desvendado (Miranda e Martins, 2008; Pinheiro, 2003), existe um consenso com relação as etapas químicas de (Boscolo) oxidação de álcoois e aldeídos para a formação de ésteres, assim como a extração, decomposição e esterificação da lignina da madeira. Nesta etapa ocorre a formação do complexo etanol-lignina, que se degradam em álcoois coniferílico e sinápico, posteriormente oxidados à esteres, que são os principais responsáveis por atribuir sabores e aromas característicos de cada madeira à cachaça.

Nesta terceira etapa ocorre também a eliminação de compostos de enxofre, como tióis, o dimetilsulfeto e mercaptanas, os quais são eliminados devido à sua elevada volatilidade.

As Figuras 9 e 10 ilustram o processo de esterificação, no qual os aldeídos e ácidos carboxílicos resultantes da fermentação e destilação reagem para formar ésteres e água. Este processo é responsável por dar a cachaça envelhecida um sabor mais suave. Após os processos descritos, a cachaça estará pronta para ser envasada e comercializada.

Figura 9: Exemplo do processo de oxidação de aladeídos à ácidos carboxílicos (Acetaldeído mais oxigênio para ácido acético ou etanóico).
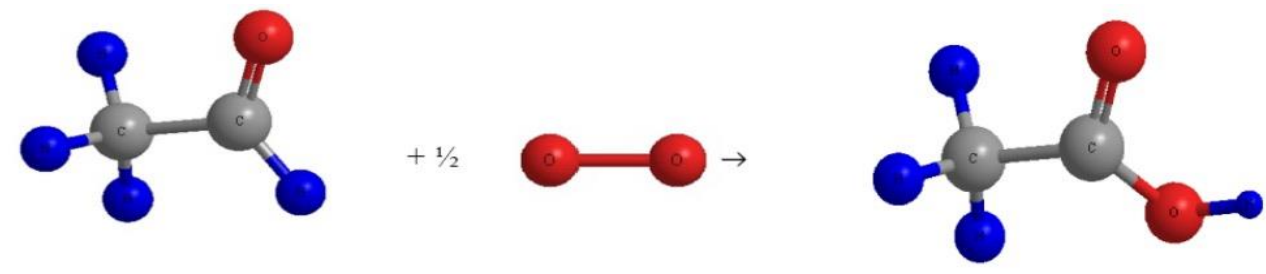

Figura 10: Exemplo do processo de esterificação de ácidos carboxílicos à esteres. (Ácido acético mais etanol para acetato de etila e água).

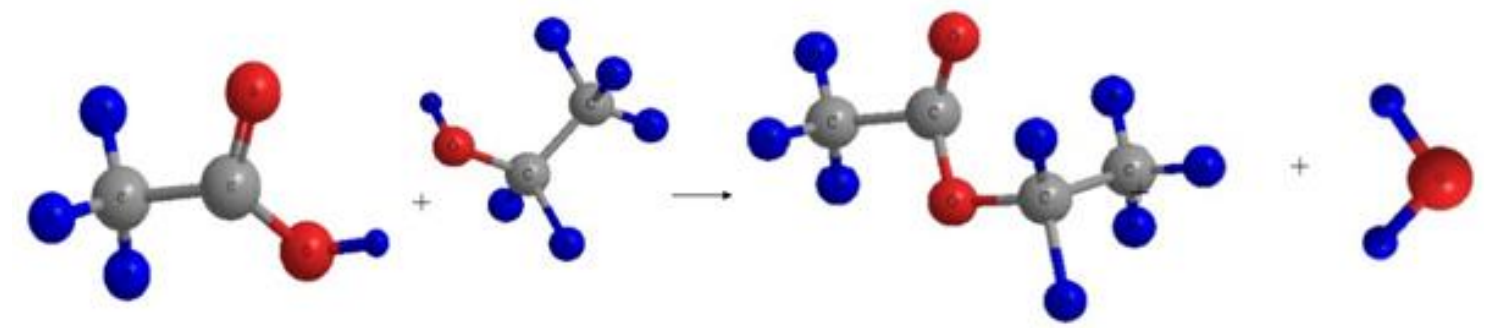

Todas as reações químicas e os processos de dissolução de compostos da madeira durante o envelhecimento da cachaça, assim como de outras bebidas alcoólicas, permitem a formação de grandes aglomerados de moléculas, incluindo os ésteres, os alcoóis superiores e os aldeídos, os quais ficam em equilíbrio com o etanol, o que é notado na forma semelhante a um óleo que escorre em volta do copo logo após ser rodado/agitado para que o líquido molhe as paredes internas. Esta formação é chamada de "choro" ou "lágrimas da cachaça" (Figura 11). 
Figura 11: Choro ou lágrimas da cachaça. Foto: Leinig Antonio Perazoli.

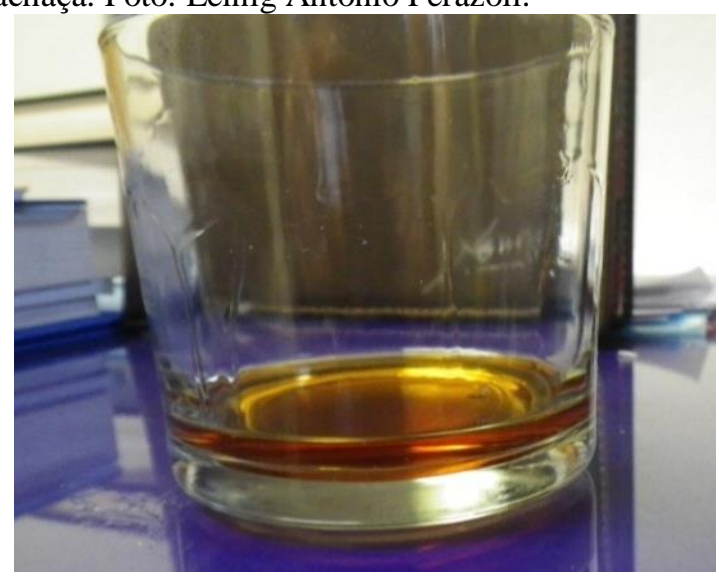

\section{A CACHAÇA NO ENSINO DE QUÍMICA}

Há diversos documentos que orientam os currículos no Brasil, como os Parâmetros Curriculares Nacionais para o Ensino Médio (PCNEM), Orientações Curriculares Nacionais para o Ensino Médio e Orientações Educacionais Complementares aos Parâmetros Curriculares Nacionais (PCN+) (BRASIL, 1999; 2006; 2002) que fazem referências à contextualização e adoção de temas como estratégias para abordagem do conhecimento científico. Nas Orientações Curriculares Nacionais para o Ensino Médio, temas do cotidiano são apontados como relevantes:

Defende-se uma abordagem de temas sociais (do cotidiano) e uma experimentação que, não dissociadas da teoria, não sejam pretensos ou meros elementos de motivação ou de ilustração, mas efetivas possibilidades de contextualização dos conhecimentos químicos, tornando-os socialmente mais relevantes. (BRASIL, 2006, p.117)

Ao partir de situações cotidianas pode-se buscar o conhecimento necessário para entendê-las e, nesse sentido, a cachaça pode ser um tema para desenvolvimento do conhecimento químico, visto que seu processo de produção envolve diversos conceitos e processos importantes relacionados à destilação, fermentação, compostos orgânicos, entre outros.

O trabalho de Pinheiro et al (2003) faz um levantamento da história, produção e da composição química da cachaça, e aponta alguns meios de o tema ser aprofundado nas aulas de química. Alguns exemplos citados são atividades com análise de rótulos, uso de letras de músicas conhecidas, presença na culinária brasileira, debates sobre seu consumo, interações entre o álcool e o organismo humano, entre outros.

Venquiaruto (2012) ao pesquisar em sua tese os saberes populares do pão, do vinho e da cachaça em uma região específica do Rio Grande do Sul, aborda o modo de produção desta bebida por campesinos. Além disso, relaciona os saberes químicos e o contexto escolar, e propõe algumas 
atividades experimentais para desenvolvimento na disciplina de química que tragam aspectos relacionados a cachaça, como a formação do azinhavre.

Os aspectos científicos e tecnológicos estão diretamente vinculados as contribuições da ciência no processo de produção, como a separação de cabeça, coração e cauda na destilação, a artefatos tecnológicos como equipamentos necessários para a destilação, assim como os aspectos sociais relacionados ao consumo do produto, seus benefícios e malefícios ao funcionamento do organismo humano e as alterações comportamentais. Portanto, apontamos que esta seria uma das abordagens possíveis para o tema cachaça em nível médio ou superior frente aos conhecimentos químicos, pois permite discutí-lo de forma ampliada, considerando aspectos da vida cotidiana e problematizando questões importantes na sociedade.

\section{CONSIDERAÇÕES FINAIS}

Cachaça é denominação por lei, típica e exclusiva da aguardente de cana de açúcar produzida no Brasil, produto estabelecido tanto nas caracterísiticas históricas, do processo de produção como nas caracterísiticas químicas. Esse trabalho estudou o processo de produção, transporte em tonéis de madeiras nacionais e o envelhecimento da aguardente de cana, exemplificando as condições históricas nos séculos XVI ao XVIII entre Paraty e Minas Gerais, unidos pela Estrada Real, que levaram a produção da cachaça, hoje reconhecida como produto genuinamente brasileiro, representando uma ferramenta interdisciplinar para o ensino de ciências tão distintas, como a História e a Química, tanto para o ensino superior como para o ensino médio. 


\section{REFERÊNCIAS}

BOSCOLO, M.; LIMA NETO, B.S., Franco D.W. O envelhecimento de aguardente de canade açúcar em tonéis de madeira. O Engarrafador Moderno, n. 41, p. 30-33, 1995.

BRASIL. Ministério da Educação, MEC, Secretaria de Educação Média e Tecnológica: Semtec. Parâmetros Curriculares Nacionais para o Ensino Médio. Brasília: MEC/Semtec, 1999. Disponível em:<<http://portal.mec.gov.br/seb/arquivos/pdf/ciencian.pdf >>. Acesso em: 10 mar. 2013.

- Ministério da Educação, Secretaria de Educação Básica. Orientações Curriculares Ensino Médio. Ciências da natureza, matemática e suas tecnologias. Secretaria de Educação Básica Brasília: Ministério da Educação, Secretaria de Educação Básica, 2006. Disponível em: <<http://portal.mec.gov.br/seb/arquivos/pdf/book_volume_02_internet.pdf〉> Acesso em: 10 mar. 2013.

- Ministério da Educação, Secretaria de Educação Básica. Orientações Educacionais Complementares aos Parâmetros Curriculares Nacionais. Brasília, 2002. Disponível em < http://portal.mec.gov.br/seb/arquivos/pdf/CienciasNatureza.pdf > Acesso em: 10 maio 2013.

CARDOSO, D.R. Aspectos da Química da Aguardente. www.semanadaquimica.org/semana17 /material/Bebidas01.pdf, acessada em Agosto de 2012.

DEWIK, P.M., Medicinal Natural Products. A Biosynthetic Approach. $2^{\circ}$ ed., John Wiley \& Sons, 2002.

FUNDAÇÃO JOAQUIM NABUCO. A Cultura do Açúcar, Fundação Joaquim Nabuco/ Massagana Multimídia Produções, episódio 1, 2006.

INFOESCOLA, http://www.infoescola.com/compostos-quimicos/lignina/ , acessada em Outubro 2012.

LIMA, A. de J.B.; CARDOSO, M. das G.; GUERREIRO, M. C.; PIMENTEL, F.A. Emprego do carvão ativado para remoção de cobre em cachaça. Química Nova, v. 29, n.2, 247-250, 2006.

MINERAÇÃO NO BRASIL COLONIAL. Disponível em: <http://www.historianet.com.br>, acessado em Novembro de 2012.

MIRANDA, J.R., História da cana de açúcar. Editora Komedi, Campinas-SP, 2008.

MIRANDA, M.B.; MARTINS, N.G.S. Perfil físico-químico de aguardente durante envelhecimento em tonéis de carvalho. Ciênc. Tecnol. Aliment., Campinas, 28(Supl.): 84-89, dez. 2008.

NOVAES, F.V. Cachaça de alambique x aguardente industrial. O Engarrafador Moderno, n. 72, p. 46-49, 2000.

ODELLO, L. et all. Avaliação sensorial de cachaça. Quím. Nova, vol.32, no.7, São Paulo, 2009. 
PERAZOLLI, L.A. et all, Moléculas químicas na história do Brasil: "o açúcar" da Escravidão às festas juninas. $6^{\circ}$ Congresso de Extensão Universitária da UNESP, Águas de Lindóia-Sp, Anais eletrônico PROEX/UNESP. ISSN nº 2176-9761. p. 0526, 2011.

PINHEIRO, P.C., LEAL, M.C., ARAUJO, D.A. Origem, Produção e Composição Química da Cachaça. Química Nova na Escola, n. 18, novembro 2003.

SANTOS, M. S.; AMARAL, C. L. C.; MACIEL, M. D. Tema sociocientífico "cachaça" em aulas práticas de química na educação profissional: uma abordagem CTS. Rev. Ensaio, v. 14, n. 01, p.227239, 2012.

SILVA, R.O. Cana de mel sabor de fel: capitania de pernambuco: uma intervenção pedagógica com caráter multi e interdisciplinar. Química Nova na Escola, v. 32, N² , maio 2010.

SILVA, B.V., NUNES DE VASCONCELOS, J. Envelhecimento de cachaça artesanal em tonéis de diversos tipos de madeira com 20L de capacidade. VIII Congresso Brasileiro de Engenharia Química em Iniciação Científica. 27 a 30 de julho de 2009, Uberlândia, Minas Gerais, Brasil, 2009.

TRINDADE, A.G., CACHAÇA: Um Amor Brasileiro. Ed. Melhoramentos, 2006.

VENQUIARUTO, L. D. O pão, o vinho e a cachaça: um estudo envolvendo os saberes populares na região do alto uruguai gaúcho. Tese de Doutorado. 2012. Universidade Federal do Rio Grande do Sul.

VENTURA, S., GIRALDEZ, R., Cachaça - Cultura e Prazer do Brasil. 1ª Edição, Damara Editora Ltda, 2006.

VENTURINI FILHO, W.G. Bebidas Alcoólicas, Ciênica e Tecnologia. Editora Blucher, São Paulo/SP, 2010. 